\title{
APORTACIONES DOCUMENTALES SOBRE LA TÉCNICA DE LA PINTURA HISPALENSE A FINES DE LA EDAD MEDIA *
}

\author{
por José María Medianero Hernández
}

Se enfoca este artículo como un repaso a las técnicas, materiales y procedimientos utilizados en pintura a fines de la etapa medieval en el ámbito geográfico de la Andalucía cristiana, todo ello a través de noticias y datos derivados de documentación de diversa índole, si bien en su mayoría proveniente del archivo catedralicio hispalense. Por estas referencias documentales se comprueba, ya en esta época, la presencia de productos y usos que serán desarrollados adecuadamente a partir del Renacimiento.

This article reviews the painting techniques, materials and procedures employed at the end of the medieval period within the geographical ambit of Christian Andalusia, using references and data from various sources, principally the Seville Cathedral archives. This documentary evidence testifies to the presence, in this early period, of products and practices which were to be suitably developed from the Renaissance onwards.

Generalmente, las consideraciones técnicas que manejamos en el análisis de la pintura bajomedieval de las distintas escuelas hispanas, justo antes de la eclosión de las novedades renacentistas, proceden del elenco habitual de la bibliografía especializada al respecto. Estos libros se basan en una serie de fuentes reduci-

* El presente trabajo fue presentado al IX Congreso del C.E.H.A. celebrado en León en octubre de 1992. Debido a que la Mesa correspondiente de dicho Congreso no consideró su admisión a causa de la falta de adecuación con el tema propuesto, aprovecho estas páginas para dar a la luz el escrito con cambios mínimos respecto a su version original. 
da y repetitiva, aceptadas como paradigmáticas para la época estudiada. En este sentido, las recetas y métodos del Libro del Arte de Cennino Cennini se tienen como modelo de los procedimientos ejecutados en cada uno de los ámbitos geográficos en el período tardomedieval. A lo sumo se matizan por fuentes posteriores de la literatura artística práctica de carácter local, que presumiblemente transmiten en su modo de hacer el peso de la tradición.

Sin embargo, es obvio que las peculiaridades en los distintos enclaves y escuelas de hecho existieron. Además de los descubrimientos técnicos obtenidos de las diferentes campañas de consolidación-traslado de murales o trabajos de restauración en tablas y otros objetos artísticos, la investigación documental puede aportar interesantes elementos de juicio para marcar estas discrepancias o variantes respecto a los métodos considerados como ortodoxos o ajustados a la tratadística medieval.

El análisis de algunos datos de naturaleza documental en este campo, referentes al ámbito sevillano, es el fin de este artículo. Fundamentalmente -aunque se aportará alguna documentación de otra procedencia y se hará referencia a tratados posteriores como el de Pacheco o el de Palomino- las noticias proceden del Archivo de la Catedral de Sevilla y en especial del Legajo 3 de la serie de Libros de Fábrica del siglo XV, fechado en 1440. Para ordenar el cúmulo informativo dividiré la exposición en cuatro apartados: Colores, Pintura Mural, Pintura en tabla y lienzo, y Pintura en otras superficies.

\section{COLORES}

En los pagos a distintos pintores se enumeran los colores y productos que necesitaron para la realización de su labor, lo cual nos permite calibrar la gama cromática utilizada, su naturaleza y los posibles métodos utilizados para la aplicación de los distintos colores. Así, en un pago del legajo arriba señalado al pintor Juan de Vargas, que trabajaba en "la casa del Relox", se expone lo siguiente:

"dile al dicho Juan de Vargas ciento e nueve maravedis e medio que compro de colores bermellon e jalde e annir e asarton e grasa e aseyte delinasa e cardenyllo e huevos e almagra que monto todo esto los dichos ciento e nueve maravedis e medio..." 1

Se repiten a continuación pagos que enumeran los mismos colores. Más adelante aparecen nuevos entre los pagos a los pintores que trabajaban en la

1. A.C.S. Libros de Fábrica. Siglo XV. Leg. 3. 1440. Fol. $25 r^{2}$. 
decoración de la portada del Cabildo Viejo catedralicio, sito en el desaparecido Corral de los Olmos:

"Iten di a Antonio sanches pintor para aseyte delinasa Veynte maraveis / Iten dile seys maravedis para asarton e ocre queson..." 2

Y a este mismo pintor:

"Iten di a Antonio sanches pintor çiento e nueve maravedis e medio que gasto en colores para la portada del cabildo en aseyte de linasa e bermellon e cardenillo e huevos e carmyn e barrnys e genolí e ocre e jalde e papel para moldes..." 3

En primer lugar la conclusión que se deriva de estos datos es que, como recomendaba Cennini, los colores "de alquimia", esto es, los colores que necesitaban para su elaboración de "artificio", no eran fabricados por los pintores sino adquiridos en las tiendas de especieros ${ }^{4}$. En segundo lugar, la presencia constante del aceite de linaza. Este extremo, que lleva a interesantes consecuencias en el apartado de procedimientos, lo trataré luego; ahora centrémonos en cada uno de los colores citados 5 .

Como es sabido, el bermellón no era más que cinabrio reducido a polvo, que adquiría un color rojo vivo. Es decir, en síntesis, sulfuro de mercurio en forma natural. Sabemos por un documento latino de 1380 que los marinos catalanes se dedicaban a la importación del "vermilione" ", pero estimo que el usado en Andalucía no era importado, contando con el yacimiento cercano de Almadén. Además estaba muy extendido el uso del bermellón artificial, obtenido por medio de la sublimación del azufre y mercurio unidos, método conocido desde época clásica y descrito por Plinio ${ }^{7}$.

2. A.C.S. IDEM. Fol. $44 v^{0}$.

3. A.C.S. IDEM. Fol. 60 vo.

4. Cennino Cennini enseña que cualquier color de este tipo "lo compres hecho, según me aconseja la práctica". Tratado de la Pintura (El Libro del Arte). Barcelona, Sucesor de E. Meseguer, 1968. Págs. 41-2.

5. La desmitificación de la invención de la pintura al óleo es un hecho ya ampliamente conocido, así como la práctica de este tipo de pintura desde muy antiguo en el muro. Vid, por ejemplo, MALTESE, C. (Coord.). Las Técnicas Artísticas, Madrid, Cátedra, 1980. Págs. 293-4 y 312. También MAYER, R. Materiales y técnicas del Arte, Madrid, 1985. Págs. 18-20.

6. Vid. COROMINAS, J. Diccionario crítico-etimológico de la Lengua Castellana, Madrid, Gredos, 1974. Tomo I, Pág. 445.

7. LAURIE, A.P. La Práctica de la Pintura, Madrid, 1935, Pág. 87. Una descripción del método para la obtención de este cinabrio o bermellón artificial se halla en PALOMINO DE CASTRO Y VELASCO, A. El Museo Pictórico o Escala Optica, Buenos Aires, Poseidon, 1944. Tomo II, Pág. 359. 
En cuanto al carmín señalado en los documentos anteriormente citados pudiera tratarse de la variedad de color extraída de la raíz de la rubia o granza, planta silvestre que se da en toda la zona mediterránea ${ }^{8}$. O bien de un pigmento derivado de un rebaje claro del bermellón.

Cercano al rojo, pero de otro matiz, debía ser el color llamado "asarton". Aunque Covarrubias afirma que "es cierta ceniça, o tierra de color açul, que haze el plomo quemado" ", se equivoca, pues el "azarcón" -así encontramos el vocablo escrito a partir del siglo XVI- era un color anaranjado muy fuerte, "color naranjado rubicundo" en palabras de Palomino ${ }^{10}$. No sabemos exactamente la composición de este color, que a veces se nombra también como "minio", aunque conocemos al menos un método de obtención que era, al parecer, calentando albayalde reducido a polvo en un recipiente de vidrio o hierro "

Similar proceso para su fabricación se seguía en el caso del color llamado "genolî", si bien se trataba de un tono amarillo. Efectivamente, también se obtenía calentando albayalde en una cazuela vidriada hasta que se pusiese amarillo ${ }^{12}$, aunque algunos autores explican también un origen vegetal ${ }^{13}$. En síntesis el "genolî", "genulî" o "genuil" -de todas estas formas se encuentra en la documentación- era un amarillo claro, pálido, muy utilizado para encarnaciones y la mezcla con añil para producir verdes.

También amarillo, aunque más vivo, era el color llamado "jalde”, vocablo procedente según el Diccionario de Autoridades del francés "jaune" 14 . Más tarde se conoció también por "oropimente", debido a que su color amarillo fuerte se acercaba al del oro. Químicamente es trisulfuro de arsénico, que puede hallarse natural o bien prepararse, muy venenoso y de resultados finales no demasiado fiables.

Dentro también de la gama de los amarillos, si bien con una variedad tonal extensa, podría clasificarse el ocre. Mejor sería hablar de "los ocres" y definirlos en general como arcillas coloridas de compuestos de hierro. Ya por procedencia natural, ya por calentamiento, se obtienen ocres de distintas tonalidades: "siena", "siena tostada", "sombra", "tierras verdes"... Los ocres se constituyen en componentes fundamentales de la pintura al fresco, respondiendo asimismo perfecta-

8. Vid. PÉREZ DOLZ, F. Iniciación a la Técnica de la Pintura, Barcelona, 1941, Pág. 99.

9. COVARRUBIAS OROZCO, S. Tesoro de la Lengua Castellana o Española, Madrid, 1611. Pág. 107.

10. El Museo Pictórico, o. c. Pág. 391.

11. IDEM, Págs. 360-1. También MONTON, B. Secretos de Artes Liberales y Mecánicas, Barcelona, 1761. Pág. 50.

12. Vid. los dos libros anteriormente citados, Págs. 360 y 51, respectivamente.

13. Vid. COROMINAS, J. o. c. Tomo II, Pág. 723.

14. REAL ACADEMIA ESPAÑOLA, Diccionario de Autoridades, Madrid, 1726 (Reed. Gredos, 1969). Tomo IV, Pág. 316. 
mente a los demás procedimientos. Pacheco da la noticia de que Luis de Vargas utilizó ocre procedente de Castilleja de la Cuesta, en las cercanías de Sevilla, para "la pintura de la Torre", es decir para los frescos que ejecutó en la Giralda ${ }^{15}$. Del Aljarafe y de las terreras del Guadalquivir lo gastarían los pintores bajomedievales hispalenses.

Muy usada en toda Andalucía fue la tierra roja llamada almagre o almagra, vocablo de origen árabe. En esencia es óxido de hierro mezclado con arcilla y otros minerales en menor proporción ${ }^{16}$. Se utilizaba tanto en pintura al fresco, en que venía a sustituir al carmín mezclándolo con cal o "Blanco de San Juan" para encarnaciones, como al temple y al óleo uniéndolo con albayalde. Los distintos tratadistas elogian el almagre de sus respectivas regiones, si bien también la abundancia de esta tierra natural en la región andaluza es manifiesta. Tanto es así que luego se conoció una tierra de este tenor con el nombre específico de "Rojo de Sevilla", centralizando quizás de forma exagerada el origen de este tipo de almagra ${ }^{17}$.

Otro color que vemos reseñado en los documentos citados es el "cardenillo", o verde cobre, también llamado "verdín" o "vermicular". Es el resultado de la corrosión del cobre por vinagre fuerte; se trata, por tanto, de un acetato cúprico bibásico. Su conocimiento es muy antiguo, pues ya Plinio cuenta su método de preparación ${ }^{18}$, aunque éste varió a lo largo de los siglos pero siempre manteniendo el principio básico de la combinación del vinagre con el cobre ${ }^{19}$. El resultado de este pigmento deja mucho que desear y sólo es aconsejable en la pintura al óleo.

Por último, aparece reseñado el "annir", esto es añil, el tinte obtenido de la "indigófera tinctórea". Todo lleva a pensar que éste sería el azul utilizado generalmente por los pintores hispalenses en la etapa bajomedieval. El llamado "azul ultramar", fabricado moliendo finamente el lapislázuli, resultaba de precio muy elevado, hasta el punto de afirmar Palomino siglos después que no se solía utilizar "sino en cosas de especial primor" ${ }^{20}$. El resultado del pigmento derivado del añil era deficiente, en especial si estaba expuesta la pintura a la interperie. Por ello, en obras de consideración y ante todo si el cliente estaba dispuesto a correr con los gastos se utilizaría excepcionalmente el "azul ultramar", como

15. PACHECO, F. Arte de la Pintura, Ed. de F.J. Sánchez Cantón. Madrid, 1956, Tomo II, Págs. 50-51.

16. BAZZI, M. Enciclopedia de las técnicas pictóricas, Madrid, Noguer, 1965. Pág. 100.

17. PÉREZ DOLZ, F. o. c. Pág. 101.

18. LAURIE, A. P. o. c. Págs. 93-4.

19. Vid. los métodos que describe PALOMINO llamándole "verdete" o. c. Tomo II, Pág. 361 y también MONTON, B. o. c. Pág. 14.

20. o. c. Tomo II, Pág. 56. 
parece desprenderse, por ejemplo, de las Ordenanzas de los Pintores de Córdo$\mathrm{ba}^{21}$.

Hay colores, muy conocidos en la época como la "Sangre de drago", que no vemos reflejado en la documentación sevillana, por lo cual hay que suponer su escasa o nula utilización ${ }^{22}$.

En ninguno de los testimonios citados aparece mención al color negro, que debía correr a cargo de los pintores, ya que su origen resultaba muy económico, fabricándolo de carbón vegetal y otras materias carbonizadas. En el ámbito hispalense se útilizaría frecuentemente el llamado "negro de vino", producto de la quema de sarmientos. Tampoco se señala la adquisición de cal, materia que el pintor debía tomar de la asignada a los albañiles en las obras de fábrica catedralicias o de otras instituciones públicas. Aunque para encargos privados tampoco sería complicado adquirirla en los numerosos "polveros" que existieron en la época. Pacheco cita por su calidad la cal de Marchena, pero siempre ha tenido fama la de Morón, mas, en realidad, nunca ha faltado este producto en Sevilla gracias a las numerosas explotaciones en las estribaciones de las cordilleras béticas. De esta cal los pintores hispalenses fabricarían el blanco para el fresco, versión del famoso "Blanco de San Juan" italiano (Bianco Sangiovanni).

\section{PINTURA MURAL}

Fue la actividad predominante de los pintores del momento en Sevilla y su zona de influencia. Ya en mi Tesis Doctoral aseveré que el fresco puro, el "buon fresco" -siguiendo la terminología italiana-, es prácticamente inexistente en Andalucía hasta la llegada del pleno Renacimiento ${ }^{23}$. Lo habitual era una pintura al temple sobre mortero calizo o, en todo caso, una técnica mixta que involucraba diferentes métodos de pintura después del secado del revoque o "fresco a

21. "Otro si ordenamos y mandamos que las colores con que se ayan de pyntar los dichos retablos sea azul fino e carmin fino de borra e lacar sinque en ello entre ningun brasil e buen genoli e non contrafecho ni puesto jalde en su lugar e buen cardenillo e buen bermellon e azarcon fino e buen albayalde fino e de aqui todas las otras colores mas bajas que son ocre prieto". A. M. C. Ordenanzas de los Pintores de Córdoba. 1493. Publicadas por RAMÍREZ DE ARELLANO, R. Inventario Monumental y Artístico de la Provincia de Córdoba, Córdoba, 1904 (Reed. por la Excma. Diputación Provincial, 1984). Pág. 342.

22. En las Ordenanzas de los Pintores de Córdoba sí lo vemos recogido: "E despues dobladas entre colores de buen bermellon e azarcon e buen naranjado fino con gran mezcla e buen verde jalde e buen cardenillo e buen albayalde e anir e sangre de drago e despues bien barnizado de buen barniz de grasa". IDEM. Pág. 343.

23. "La Pintura Trecentista en Andalucía", Tesis Doctoral inédita defendida en la Facultad de Geografía e Historia de la Universidad de Sevilla en octubre de 1987. Págs. 98-103 y 105-6. 
secco" 24 . Incluso, en los pagos antes citados de la decoración mural del Cabildo Viejo de la Catedral de Sevilla se compran, como hemos visto, aceite de linaza, barniz y huevos, lo cual nos hace pensar en una pintura al temple con aplicaciones al óleo. Además de la presencia del aceite de linaza apoya esta afirmación la compra de colores como bermellón, cardenillo, jalde o añil que no eran generalmente utilizados en la pintura al fresco de método estricto. Las menciones en este sentido abundan por doquier en la documentación manejada; para no caer en la reiteración baste este párrafo:

"Iten di a los pintores çiento e çinquenta e quatro maravedis e medio que montaron los colores que compraron / jalde e bermellon e asarton $\mathrm{e}$ Aseyte de linasa e cardenyllo e caçuelas e ollas para engrudo e huevos e almagra e anyr que montaron los dichos çiento e çinquenta e quatro maravedis e medio..." 25 .

Así pues, el aceite de linaza era utilizado de forma abundante no sólo para labores secundarias sino para la efectiva aplicación de los pigmentos, obteniendo su blanqueo probablemente mediante los métodos ya expuestos por Cennino Cennini, esto es, bien calentándolo con barniz o resinas o bien dejándolo al sol de manera prolongada en verano ${ }^{26}$.

Que el tipo de pintura mural que se practicaba era claramente al temple lo confirma, además del estudio de las obras conservadas, la documentación, al dejar suponer que los pigmentos no se integraban en el muro, como en el caso del fresco, sino que estaban pegados, superpuestos a él:

"Iten di a diego ferrnandes e Antonio sanches pintores que rayeron la pintura que estaua saltada en las bóvedas dela portada del cabildo por la renovar cada Veynte e çinco maravedis queson...".

"Iten di alos pintores ocho maravedis para cueros delixa para raspar la portada del cabildo..." 27 .

El tipo de capa de recepción de pigmentos en el muro también reitera el proceso de pintura al temple mixto sobre muro:

"Iten di a pero garcia albañyl que allano con cal las juntas dela portada del cabildo para pintarlas de nuevo Veynte maravedis... ${ }^{28}$.

24. La práctica de la técnica a "secco" a partir de la argamasa fraguada tiene unas raíces antiquísimas. Vid. en este sentido MAYER, R. o. c. Págs. 295-298.

25. A.C.S. Libros de Fábrica. Siglo XV. Leg. 3. 1440. Fol. 35 v‥

26. Tratado de la Pintura, o. c. Págs. 73-76.

27. A.C.S. Libros de Fábrica. Siglo XV. Leg. 3. 1440. Fols. $33 v^{2}$ y $37 v^{\vee}$, respectivamente.

28. IDEM, Fol. 36 vo. 
La documentación confirma asimismo que en el siglo XV se utiliza en Sevilla para la decoración mural la técnica del estarcido, esto es, a base de calcos de papel sobre cartones preparatorios, pliegos de papel que eran aplicados sobre el muro y agujereadas sus líneas con un punzón, sobre las que se vertía -"estarcía"- color para obtener en el mural el trazo deseado, luego remarcado por el pincel. En la tercera cita documental transcrita al comienzo de este artículo se compra "papel para moldes" y se repite la noticia:

"Iten di çinco maravedis a los pintores que ouyeron menester para papel para debuxar en la portada del cabildo..." ${ }^{29}$.

Las aplicaciones de oro en murales, sobre todo en nimbos y decoraciones de fondos, vendrían a seguir las técnicas tradicionales, no dejando traslucir la documentación cambios importantes, porque siempre son textos escuetos, como el pago a Antonio Sanches por dar "sisa para dorar e imprimadura para encarrnaçion enla ymagen de santa maria dela portada del cabildo" ${ }^{30}$.

\section{PINTURA EN TABLA Y LIENZO}

La utilización de la pintura al óleo en tabla en el ámbito hispalense durante el siglo XV es más difícil de asegurar dada la falta de estudios especializados en el territorio andaluz y los numerosos retoques y burdas restauraciones que han sufrido las obras conservadas a través del tiempo. Algunas tablas hacen sospechar que incluyen pigmentos con aceite de linaza, aunque la técnica predominante fue el temple cuyo vehículo de aplicación era cola o la yema de huevo. La documentación manejada tampoco descubre argumentos definitivos y todo lleva a pensar que los primeros ensayos al óleo se iniciaron en el campo de la pintura mural como hemos visto, hipótesis que se corresponde con lo estudiado en otras regiones hispanas, con testimonios tan notables como las pinturas de la Capilla de San Miguel del Monasterio de Pedralbes, ejecutadas en 1343 por Ferrer Bassa ${ }^{31}$.

Aunque evidentemente los trabajos de tablas y retablos se llevaron a cabo, lo que parece predominar según la documentación hispalense del momento en este apartado es la pintura sobre maderas encajadas en conjuntos a decorar, así como en obras festivas o arquitecturas efímeras. Son muy frecuentes, por ejemplo, los

29. IDEM, Fol. $60 \mathrm{v}^{2}$.

30. IDEM, Fol. $76 \mathrm{v}^{\mathrm{0}}$; se repiten en Fols. $77 \mathrm{v}^{2}$ y $78 \mathrm{r}^{2}$.

31. Vid. DALMASES, N. y PITARCH, A. J. Historia de L'Art Catalá S. XIV-XV, Vol. III, Barcelona, 1984. Pag. 159. 
pagos a pintores por realizar su trabajo en puertas, ventanas y otros aditamentos lígneos:

"Iten di Alfon lopes pintor porque torno a pintar las puertas dela capilla del cardenal que se destruyeron quando las tornaron a cortar los ferreros segund se contiene en Vna cuenta suya çiento e siete maravedis e medio..." ${ }^{32}$.

Asimismo la pintura en elementos mobiliarios como escabeles, atriles, escudos... o necesarios para celebraciones como cetros, andas, monumentos de madera, incluso postes o "cayados" para marcar la ruta de las procesiones, parece que ocuparon gran parte de la actividad de los pintores sevillanos de la época más que propiamente un trabajo de pintura de caballete ${ }^{33}$.

También la pintura sobre lienzo no fue una actividad primordial para los pintores hispalenses, aunque efectivamente era conocida y practicada por ellos, pero generalmente como labor secundaria con fines decorativos. Se trataba, en la mayoría de los casos, de trabajos menores tales como lienzos para cubrir ventanas o paramentos, para ostentar distintivos o configurar estandartes, para componer banderas y pendones en actos oficiales o en fiestas, etc. Sirva de ejemplo el siguiente pago por un trabajo en la Catedral de Sevilla:

"Iten di a Antonio sanches pintor quelabro en pintar Vn lienço e aparejarlo para Vna Ventana dela casa delas cuentas dela eglia Veynte e çinco maravedis..." 34 .

Los lienzos serían generalmente de lino, bien trenzados y de buena calidad, como parece indicar el siguiente párrafo señalando su procedencia genovesa:

"Di por Vn pedaço de lienço gynonisto para faser el rrey don fernando para el çirio pascual..." 35 .

32. A.C.S. Libros de Fábrica. Leg. 7. 1454. Fol. $37 \mathrm{r}^{2}$. Las citas podrían abundarse hasta la saciedad; por ejemplo en 1416 se remozó el algibe de la Plaza de San Francisco y se instalaron unas puertas en él, que fueron pintadas por Luis Lopes "El Viejo", Pintor de la Atarazana. A.M.S. Papeles de Mayordomazgo. Doc. n.. 143.

33. Sería muy largo citar ejemplos documentales al respecto. Vid. mi Tesis Doctoral. Pags. 148-183, passim y 144.

34. A.C.S. Libros de Fábrica. Siglo XV. Leg. 3. 1440. Fol. 83 vo

35. A.C.S. IDEM. Leg. 2-B. 1435. Fol. $30 \mathrm{v}^{2}$. 


\section{PINTURA EN OTRAS SUPERFICIES}

Numerosas fueron las pinturas sobre metales, por regla general en hierro, trabajo heredado de la decoración de armaduras que en los siglos finales de la Edad Media halló perfecta aplicación en el ornato de rejas y cerramientos metálicos de capillas y ventanales:

"Di a alfon lopes pyntor por las colores que puso enlas Verjas dela segunda capilla del senor cardenal que dicho auya (?) e para las pintar segund se contiene envna cuenta espresa de su mano que monto ochoçientos e treynta e VI maravedis..." ${ }^{36}$.

Muy frecuentes en la documentación tanto catedralicia como del Archivo Municipal hispalense son las labores de pinturas sobre cartón liviano o papel convenientemente preparado a base de gomas, colas, temple de huevo y yeso fino. Se nos repiten, por ejemplo, los pagos por cartas pintadas para los cirios de las procesiones, cartas que llevaban dibujados escudos, figuras o divisas al temple de huevo y también, posiblemente, con colores diluidos en aceite de linaza. Por no alargar la relación baste con este ejemplo:

"Di a diego ferrnandes pintor que començo apintar enla carta del çirio pascual el agno dei e las armas del papa e del rey e del arçobispo Veynte e çinco maravedis" ${ }^{37}$.

En otras ocasiones eran lienzos lo que colgaba de estos velones o "fachas" de cera y algunos pagos hacen pensar, incluso, en pintura directamente sobre la cera, como el efectuado en 1440 al pintor Antonio Sanches que pintaba los "cirios de flores" de las procesiones ${ }^{38}$.

Son abundantes las noticias de miniaturistas durante el siglo XV en el Archivo de la Catedral hispalense, pero de ellas no se desprenden referencias técnicas. Eso sí, parece que ya existía cierta especialización en el trabajo, dividiéndose los miniaturistas en "escribanos de letra" e "iluminadores" ${ }^{39}$.

En otras muchas superficies y materias encontramos pinturas en las décadas anteriores a la implantación de las novedades renacentistas en el ámbito sevilla-

36. A.C.S. Libros de Fábrica. Siglo XV. Leg. 7. 1454. Fol. 33 זº

37. A.C.S. Libros de Fábrica. Siglo XV. Leg. 3. Fol. $26 v^{2}$.

38. IDEM, Fols. 68 vo y $69 \mathrm{r}^{2}$.

39. Vid. por ejemplo la figura de Nicolás Gomes en mi Tesis Doctoral o. c. Págs. 156-8. 
no. Sólo dos ejemplos, a fin de no abundar en las citas, para terminar este trabajo: la pintura sobre yeserías del ya citado Antonio Sanches en la Catedral de Sevilla y la pintura de un azulejo para el Altar Mayor de Lorenzo Fernandes en $1465^{40}$.

40. A.C.S. Libros de Fábrica. Siglo XV. Leg. 3, Fol. $27 \mathrm{v}^{8}$ y Leg. 12 Fol. $33 \mathrm{v}^{2}$, respectivamente. 